\title{
POSSIBILIDADES DE DIÁLOGO ENTRE A MATEMÁTICA E A ARTE: UMA EXPERIÊNCIA NA REDE MUNICIPAL DE ENSINO DE SÃO PAULO
}

\author{
Ivan Marcos Groff ${ }^{1}$ \\ Isaura Aparecida Torse de Almeida ${ }^{2}$
}

\section{INTRODUÇÃO}

O presente trabalho teve seu início a partir das necessidades e inquietações percebidas ao longo da implantação dos novos ciclos de aprendizagem na reorganização curricular realizada pela rede municipal de ensino da cidade de São Paulo, a partir da publicação da portaria 5.930/13 - SMESP de 14/10/2013. Nossa experiência inicia no ano letivo de 2015 quando sentimos a necessidade de planejarmos ações conjuntas frente aos sextos anos que estavam na reta final do ciclo interdisciplinar como consta na legislação municipal:

Ciclo Interdisciplinar: compreendendo do $4^{\circ}$ ao $6^{\underline{0}}$ anos do Ensino Fundamental, com a finalidade de aproximar os diferentes ciclos por meio da interdisciplinaridade e permitir uma passagem gradativa de uma para outra fase de desenvolvimento, bem como, consolidar o processo de alfabetização/ letramento e de resolução de problemas matemáticos com autonomia para a leitura e a escrita, interagindo com diferentes gêneros textuais e literários e comunicando-se com fluência e com raciocínio lógico. (portaria 5.930/13 - SMESP de 14/10/2013, art. 5ํ).

As ações conjuntas foram planejadas entre as linguagens da Matemática e das Artes Visuais, para o início dos trabalhos pedagógicos na EMEFM "Guiomar Cabral" situada no bairro de Pirituba. O principal eixo pensado foi a integração entre os currículos, os quais iriam se complementar e entrelaçar ao longo do processo. Desde o princípio nossas ideias eram desenvolver conhecimentos e propor ações práticas que ocorressem numa sequência simultânea com a intenção de viabilizar um processo de aprendizagem com sentido e vivências, onde a contextualização e a compreensão da proposta interdisciplinar fossem praticadas e refletidas entre os educadores e os estudantes.

Ao encontro de nossos anseios a Secretaria Municipal de Ensino de São Paulo convidou os professores a participarem de um curso de formação continuada

\footnotetext{
'EMEFM "GUIOMAR CABRAL" ivangroff@gmail.com

2 idem

maeiata@gmail.com
} 
que seria nosso ponto de debates e reflexões sobre as práticas pedagógicas interdisciplinares que ocorriam nas unidades escolares. Iniciamos o curso "Diálogos interdisciplinares a caminho da autoria: elementos conceituais e metodológicos para a construção dos direitos de aprendizagem do ciclo interdisciplinar", que foi oferecido em encontros presenciais mensais e complementou as reflexões que já fazíamos sobre a prática diária em sala de aula e das dificuldades enfrentadas durante 0 processo ensino aprendizagem, uma vez que existe sempre uma busca de metodologias que auxiliem a tarefa de ensinar. Tivemos a oportunidade de refletir, através de diálogos entre os educadores participantes, questões referentes à construção dos direitos de aprendizagem dos estudantes do Ciclo Interdisciplinar.

\section{FUNDAMENTAÇÃO TEÓRICA PARA OS DIREITOS DE APRENDIZAGEM}

Na segunda metade do século XX a abordagem do construtivismo trouxe para o meio educacional o questionamento sobre a interdisciplinaridade, a partir da premissa de que o aluno dever ser compreendido por completo através de uma base curricular integrada que proporcione novas formas de aprender.

De acordo com Paulo Freire:

a interdisciplinaridade é o processo metodológico de construção do conhecimento pelo sujeito com base em sua relação com o contexto, com a realidade, com sua cultura. Busca-se a expressão interdisciplinaridade pela caracterização de dois movimentos dialéticos: a problematização da situação, pela qual se desvela a realidade, e a sistematização dos conhecimentos de forma integrada. (FREIRE, Rio de Janeiro, 1987).

Nos Parâmetros Curriculares Nacionais a interdisciplinaridade é apresentada como uma forma de prática de ensino, uma vez que apresenta uma visão crítica e pode ser entendida como uma maneira de superar a visão de conhecimento fragmentado.

Nos estudos realizados compreendemos que existem duas formas de interdisciplinaridade uma científica e outra escolar. Na concepção de Ivani Fazenda (1998) a primeira está voltada para a produção de novos conhecimentos enquanto a segunda tem por finalidade a difusão do conhecimento, favorecendo a integração das aprendizagens pelo estabelecimento de ligações complementares entre as disciplinas. 
Para Frigotto (1995, p. 26), "a interdisciplinaridade surge pela própria forma de o homem produzir-se enquanto ser social e enquanto sujeito e objeto do conhecimento social". Complementar a essa ideia as relações sociais terão uma condição mais benéfica para os processos de aprendizagens quando estas estabelecem uma relação de cooperação, entre os agentes da aprendizagem, compreendendo assim educadores e estudantes em situações diversas nos contextos de interdisciplinaridade.

Para garantir a apropriação do conhecimento é necessário criar estratégias para a aprendizagem do estudante, de acordo com sua fase de desenvolvimento, bem como é essencial que exista uma relação dinâmica da criança com o conteúdo a ser aprendido. Tais estratégias favorecem a aprendizagem, especialmente na infância, devendo ter foco a observação, a pesquisa, o desenho, o registro, o levantamento de hipóteses, ou seja, situações que problematizem o conhecimento.

Não podemos inviabilizar o protagonismo das crianças, pois o processo de ensino e aprendizagem acontece por meio de relações de comunicação entre as crianças e entre crianças e adultos.

Nesse sentido, Freire (1996, p.52) enfatiza a necessidade dos educadores criarem as possibilidades para a produção ou construção do conhecimento pelos estudantes, numa perspectiva autônoma, compreendendo que "[...] ensinar não é transferir conhecimento, mas criar as possibilidades para sua própria produção ou a sua construção".

Com vistas às especificidades do ciclo interdisciplinar e da faixa etária de sextos anos compreendendo os 11 e 12 anos, reportamo-nos à Epistemologia Genética de Jean Piaget, segundo a qual corresponde ao estágio operatórioconcreto, onde surge a reversibilidade como propriedade das ações da criança, ajudando na construção de novos invariantes cognitivos, desta vez de natureza representativa. Piaget (1974, pg. 52) "no sentido restrito, só falaríamos de aprendizagem na medida em que um resultado, conhecimento ou atuação é adquirido em função da experiência".

O enfoque numa visão holística de educação também contribui para a garantia dos direitos da aprendizagem principalmente quando estabelecemos a relação entre 'corpo e mente'. Para Cardoso (1995) devemos considerar o estudante como um ser original que faz parte de um contexto social e cultural e o educador 
deve pensar nas possibilidades de atingir as múltiplas inteligências. $O$ autor ainda enfatiza que as relações intra e interpessoais favorecem a construção coletiva do conhecimento, possibilitando aos estudantes compartilhar entre si os avanços, reflexões e dificuldades construindo as aprendizagens.

Educar significa utilizar praticas pedagógicas que desenvolvam simultaneamente razão, sensação, sentimento e intuição e que estimulem a integração intercultural e a visão planetária das coisas, em nome da paz e da unidade do mundo. (CARDOSO, 1995, p. 53)

Um conceito importante que foi proposto por Vygotsky (1998) é a zona de desenvolvimento proximal, ou seja, a distância entre aquilo que o estudante sabe e consegue fazer sozinho, daquilo que ele pode vir a aprender com a ajuda de outros. Neste momento de desenvolvimento é quando o educador deve fazer sua intervenção, ou seja, a mediação.

Ao utilizar o conceito de zona de desenvolvimento proximal, o estudante e o educador tem a possibilidade de enfrentar novos desafios. Assim o adulto deve oferecer à criança as oportunidades significativas para construção de conhecimentos, promovendo a interação e a cooperação através de situações mediatizadas, que proporcionem um novo significado ao processo de aprendizagem.

O papel do professor terá a incumbência da não fragmentação, para isso faz-se necessário a quebra de paradigmas arraigados nas concepções da educação tradicional e bancária as quais Paulo Freire tanto questiona e propõe transformações na postura do educador para que transcenda a reprodução para a produção do conhecimento.

\section{PROPOSTA INTERDISCIPLINAR}

Segundo o ECA, considera-se criança, para os efeitos desta lei, a pessoa até doze anos de idade incompletos, nesse sentido na elaboração das nossas ações pedagógicas tínhamos como foco a aprendizagem a partir da ludicidade, contemplando as especificidades da faixa etária do ciclo interdisciplinar entre 9 e 11 anos e as linguagens da matemática e artes visuais. Através das reflexões sobre nossas ações e a garantia aos direitos de aprendizagens previstos nos documentos oficiais sobre ciclos de aprendizagens da SME/SP, constatamos: 
Nesse processo, ainda que existam especificidades em cada um dos ciclos de aprendizagem do Ensino Fundamental, há uma riqueza de possibilidades de construção de conhecimento pela criança que deve ser considerada, a saber: a imaginação, a criatividade, o movimento, a livre expressão, as diversas situações de interação entre os pares, a exploração do mundo ao seu redor e as múltiplas linguagens presentes nesse universo (DIALOGOS INTERDISCIPLINARES A CAMINHO DA AUTORIA, SME/SP, 2015).

Para garantir os direitos de aprendizagem também se faz necessário estimular o protagonismo dos estudantes, realizar práticas pedagógicas que compreendam a diversidade e as diferenças entre sujeitos que pensam e criam culturas e pensar nas contribuições de diferentes áreas.

Conforme os estudos de Esteban Levin (2001) as relações entre o corpo e os gestos são essenciais para a formação geral do ser humano, pois desde a mais tenra idade a criança usa a linguagem corporal para conhecer a si mesma, para relacionar-se com outras pessoas e descobrir o mundo. Os aprendizados se tornarão efetivos na infância quando a linguagem corporal e o uso dos gestos serão utilizados na aprendizagem e facilitam a memória infantil.

[...] a corporeidade é, existe e possui, através da cultura, significado. Daí a constatação de que a relação corpo-educação, por meio da aprendizagem, significa aprendizagem da cultura - dando ênfase aos sentidos dos acontecimentos e aprendizagem da história - enfatizando aqui a relevância das ações humanas. Corpo que se educa é corpo humano que aprende a fazer história fazendo cultura (MOREIRA, 2012, p.135).

Nossa proposta de trabalho pedagógico ancorou-se na cultura da corporeidade, sendo o corpo como desencadeador das propostas de trabalho prático entre as duas linguagens abordadas.

O fazer artístico das crianças ocorreu a partir dos estímulos gerados pelas imagens dos papiros egípcios, foi proposto uma ação criativa coletiva que durou cerca de seis aulas, que consistiu na construção de silhuetas dos seus próprios corpos, utilizando diferentes técnicas desde o uso de lápis de cor e tinta até as possibilidades de colagens. As silhuetas foram criadas inicialmente nas aulas de artes, mas tiveram usos também nas aulas de matemática quando nas sequencias de aulas eram propostas atividades relacionadas à simbologia das medições que ocorriam na antiga cultura egípcia as quais utilizavam partes do corpo humano para nomear e identificar formas e maneiras de quantificar medidas. Os conhecimentos 
prévios dos estudantes se entrelaçavam com dos educadores que realizavam também a mediação pedagógica.

Os processos de percepção se interligam com os próprios processos de criação. O ser humano é por natureza um ser criativo. No ato de perceber, ele tenta interpretar e, nesse interpretar, já começa a criar. Não existe um momento de compreensão que não seja ao mesmo tempo criação. (NOVAES, 1988, p.167).

Listamos no quadro abaixo as relações estabelecidas entre as linguagens:

\begin{tabular}{|c|c|}
\hline \multicolumn{2}{|c|}{ Dialogo entre a Arte e a Matemática, através da simbologia egípcia: } \\
\hline Arte & Matemática \\
\hline Leitura de Imagens & História da Matemática \\
\hline Representação egípcia - lei da frontalidade & Sistema de numeração egípcio \\
\hline Construção de silhuetas & Recursos/medidas - o corpo como medida \\
\hline
\end{tabular}

Tabela elaborada pelos autores

Para Read (2001, p. 56) "Uma imagem visual é a forma mais perfeita da representação mental onde quer que se faça referência à forma, posição e relações dos objetos no espaço.". A presença da imagem foi essencial em todo o processo de aprendizagem e teve como foco a ampliação do repertório pessoal de cada um dos participantes por meio das trocas com os seus pares.

A interação entre sujeito-sujeito ou de sujeito-ambiente é decisiva no processo de aprendizagem e se concretiza no ato de se produzir as próprias imagens mentais e as relacionar com as experiências pessoais tornam-se um meio de criação.

A educação sob a perspectiva de formar a consciência sensorial tem nas relações corporais uma aliada. O reconhecimento do corpo como elemento simbólico faz parte da natureza humana e compõem desde a mais remota época imagens elementares da criação artística. 
De acordo com os Elementos Conceituais e Metodológicos para Definição dos Direitos de Aprendizagem e Desenvolvimento do Ciclo de Alfabetização (1ํㅜ $2^{\circ} \mathrm{e}$ $3^{\circ}$ anos) do Ensino Fundamental:

No ciclo interdisciplinar, como no ciclo de alfabetização, a importância da utilização de uma linguagem simbólica e universal traz em seu bojo a oralidade matemática. O falar e o conversar sobre Matemática, na explicitação de pontos de vista, são importantes ações de letramento e aprendizagem matemáticos. (BRASIL, 2012, pg. 68).

Evidenciamos que não é a aprendizagem de cálculos que efetiva a aquisição de conceitos matemáticos, mas sim os instrumentos que abrem uma janela para uma reflexão crítica sobre o que está sendo estudado podendo ser utilizado em outros contextos da vida cotidiana.

Incentivar uma relação entre o aprender com o próprio corpo são práticas que deveriam ser cultivadas por toda a escolaridade. Segundo Levin (2001), até o início da puberdade, entre os 12 ou 13 anos, as relações da corporeidade são determinantes. Quando ocorre algum aprendizado pela primeira vez, precisa ser marcante e positivo, ainda que inconsciente. $O$ uso do corpo permitirá que essas lembranças sejam prazerosas e a criança irá associar o aprendizado às boas sensações.

Durante todo o processo os estudantes foram sendo envolvidos nos conceitos que a matemática e a arte traziam associados às relações corpóreas e simbólicas. A simbologia foi tratada como uma criação da inteligência humana no decorrer das diferentes épocas e que na atualidade usamos os símbolos que nos transmitem seus significados conforme cada sociedade e cultura.

Para melhor compreendermos o papel do símbolo e seus sentidos buscamos em Gilbert Durand alguns esclarecimentos sobre a estrutura filosófica do conceito sobre os arquétipos imagéticos que acompanham a história da humanidade. Segundo Durand (1996) "os arquétipos são a via de diferenciação perceptiva e da distanciação exógena." Ele ainda exemplifica as influencias do mundo exterior como fontes criadoras de simbologia quando relata:

[...] o cortejo simbólico do sol a erguer-se das montanhas ou terras desérticas, ligado à cor dourada das areias, adquire, nos antigos Mexicanos - o sol nasce do húmido golfo do México donde sopram ventos pluviosos - 
tons de turquesa, e o brilho do astro ao subir impregna-se dos símbolos da fecundidade vegetal. (DURAND, 1996, p.76)

Durand exalta aqui a complexidade que existe no conceito de símbolo e mais adiante propõe que sua perpetuação se dará justamente através da permanência da plurivocidade dos significados como relata "(...) o signo arquétipo perde a sua equivocidade e o significante desliga-se cada vez mais do significado (...)".

Em cada aula ocorreu um processo interativo de aprendizagem, que, como diz Vygotsky, depende de condições externas e internas. As construções cognitivas dos estudantes são influenciadas por tais condições e demais recursos didáticos.

Um conceito importante que foi proposto por Vygotsky (1998) é a "zona de desenvolvimento proximal", ou seja, a distância entre aquilo que o estudante sabe e consegue fazer sozinho, daquilo que ele pode vir a aprender com a ajuda de outros. Neste momento de desenvolvimento é quando o educador deve fazer sua intervenção, ou seja, a mediação.

Respeitando os diferentes tempos de aprendizagens e proporcionando a aprendizagem por meio das vivências de grupo fomos trilhando nossas ações sempre com o propósito de fazer um trabalho cooperativo, no qual uma criança aprende com a outra e a mediação pedagógica ocorreu sempre que os educadores perceberam a necessidade de intervir.

Ao utilizar o conceito de zona de desenvolvimento proximal, o estudante e o educador tem a possibilidade de enfrentar novos desafios. Assim o adulto deve oferecer à criança as oportunidades significativas para construção de conhecimentos, promovendo a interação e a cooperação através de situações mediatizadas, que proporcionem um novo significado ao processo de aprendizagem.

\section{RESULTADOS E DISCUSSÕES}

Com o desenvolvimento desta possibilidade interdisciplinar constatamos que a concepção de alfabetização matemática e de arte foi contemplada pelo uso de símbolos e imagens da cultura egípcia, que através das atividades desenvolvidas os 
estudantes realizaram seus registros individuais e coletivos verificando aprendizagens relacionadas à compreensão, interpretação e comunicação de ideias.

Para nossa proposta de trabalho interdisciplinar a imagem teve uma importância fundamental tanto para iniciarmos e durante todo o processo, como para a conclusão do mesmo. Certamente, proporcionou mudança no paradigma do olhar sobre o ensino e sobre a aprendizagem em nossa prática docente. A partir de estudos sobre as imagens e como elas nos influenciam no tempo e no espaço e nos diferentes contextos sócio culturais. Para Ana Mae Barbosa (2008) as imagens estão inseridas no cotidiano das pessoas e exercem forte influência sendo um componente central da comunicação, por meio de sua multiplicidade cultural e amplitude de difusão tem como fator determinante a questão da materialidade como prolongador de sua existência no tempo.

O ponto de partida deste trabalho foram nossas inquietações sobre a não fragmentação de conteúdos e a participação no Curso "Diálogos interdisciplinares a caminho da autoria: elementos conceituais e metodológicos para a construção dos direitos de aprendizagem do ciclo interdisciplinar", que auxiliaram nas ações que romperam com os moldes tradicionais de aprender e educar.

Tivemos a aplicação da proposta de despertar nos estudantes a percepção de que os conhecimentos se fundem e que na vida prática exige-se a compreensão do todo. Acreditamos que foi semeada a ideia de não fragmentação de conteúdos e que os símbolos foram elementos determinantes nas relações interdisciplinares estabelecidas. A inserção da imagem da silhueta no desenvolvimento das atividades produziu um resultado positivo na aprendizagem, pois através da visualização e interação com o objeto de estudo as crianças puderam sentir-se mais autônomas e puderam demonstrar seus conhecimentos.

Nas atividades as dúvidas, erros e angustias, foram extremamente positivas no tocante a provocar reflexões e puderam ser comparadas ao próprio processo de construção pelos quais passaram as pessoas, quando desenvolvem atividades artísticas e matemáticas, em seus contextos e épocas.

\section{CONSIDERAÇÕES FINAIS}

A ressignificação da prática, a partir das reflexões ocorridas no curso de formação conduziu os estudantes o que Morin (2003) chamou de a abertura de 
perceber o novo, pois proporcionamos uma atividade baseada na interação e descoberta de novos conhecimentos.

Realizando as atividades através de uma ponte entre a arte e a matemática, abrangemos o conteúdo de forma ampliada e integrada, valorizando o processo de aprendizagem através da participação efetiva do estudante.

Salientamos que a transformação da forma de ensinar que utilizamos na sequencia de atividades foi possibilitada a partir das reflexões proporcionadas no curso de formação, assim reiteramos a importância e necessidade de promover cursos de formação docente com o intuito de atingir as expectativas de melhoria na qualidade da educação e que contemplem as necessidades dos discentes, criando um elo que possibilite aos docentes envolvê-los na prática construída no seu dia a dia embalado pela ação-reflexão-ação.

Diante disso, pode-se concluir que a formação contribuiu para potencializar o ensino e colaborar para a abertura de novas formas de aprender e ensinar, através da possibilidade didático-pedagógica da interdisciplinaridade, assim estas questões teóricas e praticas são de grande importância para o constante processo de formação continuada que potencializam o trabalho na sala de aula.

\section{REFERÊNCIAS}

BARBOSA, Ana Mae. A imagem no ensino da Arte. São Paulo: Perspectiva, 2008.

BRASIL. Ministério da Educação. Secretaria de Educação Básica. Diretoria de Currículos e Educação Integral - DICEI. Coordenação Geral do Ensino Fundamental - COEF. Elementos conceituais e metodológicos para definição dos direitos de aprendizagem e desenvolvimento do ciclo básico de alfabetização (1ㅜ, 2은 anos) do ensino fundamental. Brasília, DF: MEC, 2012.

BRASIL. Ministério da Educação e do Desporto. Secretaria de Educação Fundamental. Parâmetros curriculares nacionais terceiro e quarto ciclos do ensino fundamental. Brasília, DF: MEC/SEF,1998.

CARDOSO, Clodoaldo M. A Canção da Inteireza: uma visão holística da educação. São Paulo: Summus, 1995.

DURAND, Gilbert. Campos do imaginário. Lisboa: Instituto Piaget, 1996.

FAZENDA, Ivani (Org.). Didática e interdisciplinaridade. Campinas: Papirus, 1998.

FREIRE, Paulo. Pedagogia da autonomia. Rio de Janeiro: Paz e Terra, 1996.

FRIGOTTO, Gaudêncio. A interdisciplinaridade como necessidade e como problema nas ciências sociais. In: JANTSCH, Ari Paulo; BIANCHETTI, Lucídio 
(Orgs.). Interdisciplinaridade: para além da filosofia do sujeito. Petrópolis: Vozes, 1995.

LEVIN, Esteban. A infância em cena. São Paulo: Vozes, 2001.

MOREIRA, W. W. Formação Profissional em Ciência do Esporte: Homo Sportivus e Humanismo. In: BENTO, J. O; MOREIRA, W. W. O Homo sportivus: o humano no homem. Belo Horizonte: Instituto Casa da Educação Física, p.127-178, 2012.

MORIN, Edgar. Os sete Saberes Necessários à Educação no Futuro. São Paulo. Cortez, 2003.

NOVAES, Adauto. O Olhar. São Paulo: Companhia das Letras, 1988.

PIAGET, Jean. Estudos Sociológicos. Rio de Janeiro: Forense, 1973.

READ, Herbert. A Educação pela Arte. São Paulo: Martins Fontes, 2001.

SÃO PAULO. Secretaria Municipal de Educação de São Paulo. Diálogos interdisciplinares a caminho da autoria. Elementos conceituais e metodológicos para a construção dos direitos de aprendizagem do Ciclo Interdisciplinar. São Paulo, SP, 2015.

SÃO PAULO. Secretaria Municipal de Educação de São Paulo. Portaria 5.930/13 SME de 14/10/2013. Diário Oficial do Município. São Paulo, SP, 2013.

VYGOTSKY, L. S. A Formação Social da Mente: o desenvolvimento dos processos psicológicos superiores; organizadores. Michael Cole (et al), 6a. ed. São Paulo: Martins Fontes, 1998. 